\title{
Nota editorial
}

\section{Condiciones de escritura}

\section{Carlos Kuri}

...hay el amor a la palabra como objeto material

J-P. SARTRE

La pregunta del título de Freud de I9 I9: “¿Se debe enseñar psicoanálisis en la universidad?”, podemos transcribirla y replicarla hoy en ¿Se debe escribir psicoanálisis en la universidad? De inmediato, de manera polifónica, hay que decir que mientras las dos preguntas siguen vigentes, y provocando consecuencias diversas, existe el psicoanálisis en la universidad, y penetrado con otra pregunta por sus efectos.

Una revista de psicoanálisis en la universidad, con las condiciones que la época de la academia ha impuesto sobre las investigaciones, de modelos de restricción formal y de control burocrático concomitante, nace con todas las posibilidades de caer en un nido de trampas. Sabemos de la selva de confusiones que precede y envuelve al psicoanálisis en la universidad; desde el doble movimiento freudiano que requería la entrada del psicoanálisis y la defensa simultánea al psicoanálisis lego. No deja de mantener ese tono paradojal el hecho de que actualmente siga operando una fuerza centrífuga, que temerosamente procura impedir que la universidad fagocite al psicoanálisis. ¿Cómo cuidar al psicoanálisis de la aceptación e incorporación universitaria? Si bien Freud planteaba que la formación del analista podría prescindir de la universidad (sin desconocer que justamente parte de ese planteo era correlativo a la exclusión que el psicoanálisis sufría), la idea respondía (y responde) en términos generales a la incompatibilidad de la práctica con cualquier título. Que esta revista sirva probablemente para que profesores de la Facultad de Psicología, que son (o trabajan -para no abusar de la ontología- de) psicoanalistas, consigan un recurso académico y administrativo para sus concursos y carrera docente no debiera empujarnos a identificar esto con una resignación o retroceso del psicoanálisis ni tampoco, querría, a un descuido por la escritura, por el amor a la palabra como objeto material.

Por otra parte, el ejercicio lacaniano de intervenir con el inconsciente (esto es, con los cuatro discursos en el giro del discurso universitario) a la institución universitaria, ha congestionado nuevas contradicciones y fomentado nue- 
vas paradojas de resguardo: salvarse de ser universitario para ser psicoanalista (¿de escribir como universitario para escribir como psicoanalista?). Fobia que viene con la superstición de que la exterioridad a lo académico preserva de la confiscación del discurso psicoanalítico en manos del idioma de "ciencia y tecnología". Como si el discurso pudiera disciplinarse con requisitos institucionales, en lugar de observar el movimiento indócil con que performa lugares, acciones y escrituras. Sin embargo, la aprensión del lacanismo, con un sesgo de hipocresía, ha sancionado la impropiedad de la escritura psicoanalítica en el territorio académico, confundiendo discurso y territorio. Esto no equivale a desconocer las razones que advierten de las trampas que acechan al psicoanálisis en la universidad; pero no debiéramos confundirnos en la idealización de un campo, institucional o existencial donde el psicoanálisis viva, investigue y escriba en estado 'natural'. No es difícil percibir la alienación universitaria de las Escuelas de psicoanálisis, o, al revés, considerar incluso - tal la concepción de Irene Friedenthal en ocasión de unas jornadas de psicoanálisis—a la Facultad de Psicología como Institución psicoanalítica.

La escritura que invoca el psicoanálisis y que lo constituye, interroga las condiciones de su escritura, y en este caso resulta difícil no considerar uno de los rasgos de este tipo de revistas: el sistema de referato. Mantener el secreto de los nombres, quién escribe, quién lee evaluativamente; por supuesto las consecuencias pueden bifurcarse: secreto para que el nombre no incida sobre la lectura de la evaluación ni eclipse la enunciación, que pueda leerse sin la subjetividad, para oír algo del sujeto que nace del escrito (el autor foucaultiano en definitiva). El sistema de doble ciego -ni autor ni evaluador deben saber del otro-: ¿hay que estar doblemente ciego para leer mejor? No deja de mantener latente la duda, y hay que trabajar con ella, sobre cuánto afecta de alteración perniciosa la versión de la alteridad que es el otro como réferi.

La revista, que convoca a psicoanalistas y a intelectuales (ojalá no sean rasgos excluyentes) vinculados de una u otra manera con la universidad, ofrece, y esta es una de sus singularidades, ocasión para diferentes combates. En cuanto a la escritura misma, con lo que se mezcla de escribiente - que refleja procedimientos académicos de investigación-, y de escritor — que constituye al mismo tiempo indagación y estilo. Pero con esa tensión 'escrituraria' vienen otras ¿̇por qué no pensar la revista como caja de resonancia de las disputas clínicas contemporáneas que hallan en la Facultad una especie de neutralidad? Recordando los argumentos de Freud ante aquella universidad, al advertir que la enseñanza médica era lagunosa por dejar de lado los factores psíquicos, de la anatomía, la física y la química, podemos hallar ahora el retorno invertido de aquella controversia. Las derivaciones psicoterapéuticas de las neurociencias se han dedicado a eliminar directamente el nombre del sujeto, con su sede atópica en el lenguaje. Se ha creído poder suprimir la pregunta del sujeto sobre la causalidad abismal del sufrimiento, como la medicina suprimió la tuberculosis o la lepra (invoco, 
claro está, la conocida refutación al presagio médico que Foucault hace en Historia de la locura).

Habría que incluir en este repertorio de tensiones, la remisión e interferencia entre habla y escritura. Los analistas que enseñan en la universidad ¿dejan en sus textos, los aquí publicados por ejemplo, la huella de la voz áulica? ¿Encontramos en los textos, la escritura de aquello que no pasó la prueba de la enseñanza? ¿Los tropiezos de la pedagogía prosiguen en estas páginas, como la causa de estos ensayos? (el punto extremo sería aquí la publicación de una clase escrita). De suceder algo de esto, podríamos interpretar la afirmación de Lacan: lo no-enseñable se encuentra en la raíz de la escritura, y que en este caso compone una revista derivada principalmente de cátedras de psicoanálisis. ${ }^{1}$

Digamos finalmente, como apuesta, como anhelo, que la revista pueda tramitar esta serie abierta de conflictos, ofreciendo la contingencia para una escritura que provenga del 'sentimiento de pérdida de sentido' del mundo psi, ensayos exteriores a cualquier Baedeker psicoanalítico, exteriores a la parodia de revista científica compuesta por textos guías de nuestra práctica. ${ }^{2}$

1 Estoy pensando en la dinámica de diferencias superpuestas -escritura, matema, decir, dicho, enseñanza- que Lacan hace en L'etourdit. "Así, un decir tal como el mío, es por existir al dicho que él permite su matema, pero no hace para mí matema y se plantea así como no enseñable antes que el decir se haya producido, como enseñable solamente después que yo lo he matematizado según los criterios menonianos que sin embargo me lo habían certificado".

2 "Yo no soy en modo alguno partidario de fabricar cosmovisiones. Dejémoslas para los filósofos, quienes, según propia confesión, hallan irrealizable el viaje de la vida sin un Baedeker (guías turísticas publicadas en Alemania por Karl Baedeker) así, que dé razón de todo". S. Freud, "Inhibición, síntoma y angustia”, Obras Completas (Vol. 20), Amorrortu, Buenos Aires, I977. También: JINKIS, J., "Discursionarios" en Revista Conjetural 47, Ed. Sitio, Buenos Aires, 2007. 